\title{
ESTUDO FORMATIVO SOBRE LETRAMENTO CIENTÍFICO E CIBERCULTURA
}

\section{STUDY ON SCIENTIFIC LETTERING AND CIBERCULTURE}

\section{ESTUDIO FORMATIVO SOBRE LITERACÍAS CIENTÍFICAS Y CIBERCULTURA}

Irene Pena Bittencourt ${ }^{1}$

\section{INTRODUÇÃO}

O objetivo do presente texto é apresentar uma resenha crítica acerca do livro New Literacies, new agencies?: a Brazilian perspective on mindsets, digital practices and tools for social action in and out of school organizado por Eduardo S. Junqueira ${ }^{2}$, líder do grupo de pesquisa Linguagens e Educação em Rede (LER), coordena pesquisas sobre navegação hipermodal em contextos de aprendizagem com o uso da técnica de rastreamento ocular (eye tracking) e Marcelo E. K. Buzato ${ }^{3}$, Professor Doutor MS3 da Universidade Estadual de Campinas, atua principalmente na área de concentração Linguagem e Sociedade, nas linhas de pesquisa Linguagens e Tecnologias. Dessa forma, trazendo reflexões e análises a respeito de cada capítulo presente no livro baseadas no fazerpesquisa ${ }^{4}$, na metodologia da Pesquisa Formação do Grupo de Pesquisa Docência e

Submetido em: 13/05/2018 - Aceito em: 17/05/2018 - Publicado em: 30/06/2018.

${ }^{1}$ Graduanda em Licenciatura em Letras pela UERJ, Professora do curso Pré Vestibular Transformar e membro do GPDOC - Grupo de Pesquisa Docência e Cibercultura, Tutora de Língua Portuguesa na E.M. Maranhão. Email: irenebittenncourt@gmail.com

${ }^{2}$ http://lattes.cnpq.br/7443323966791424

${ }^{3}$ http://lattes.cnpq.br/5005283630149329

4 “Adotamos o uso dos termos espaçostempos, fazeressaberesfazeres, dentrofora, entre outros, escritos de forma diferenciada, pois nos inspiramos no referencial teórico de Alves (2008) sobre as pesquisas nos/dos/com os cotidianos. Para a autora: "A junção de termos e a sua inversão, em alguns casos, quanto ao modo como são 'normalmente' enunciados, nos pareceu, há algum tempo, a forma de mostrar os limites 


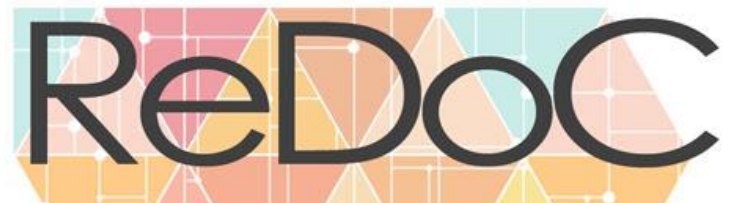

Revista Docência e Cibercultura

Cibercultura, coordenado pela professora Edméa Santos. Além disso, trazendo um relato breve a respeito da intinerância da bolsista de Iniciação Científica.

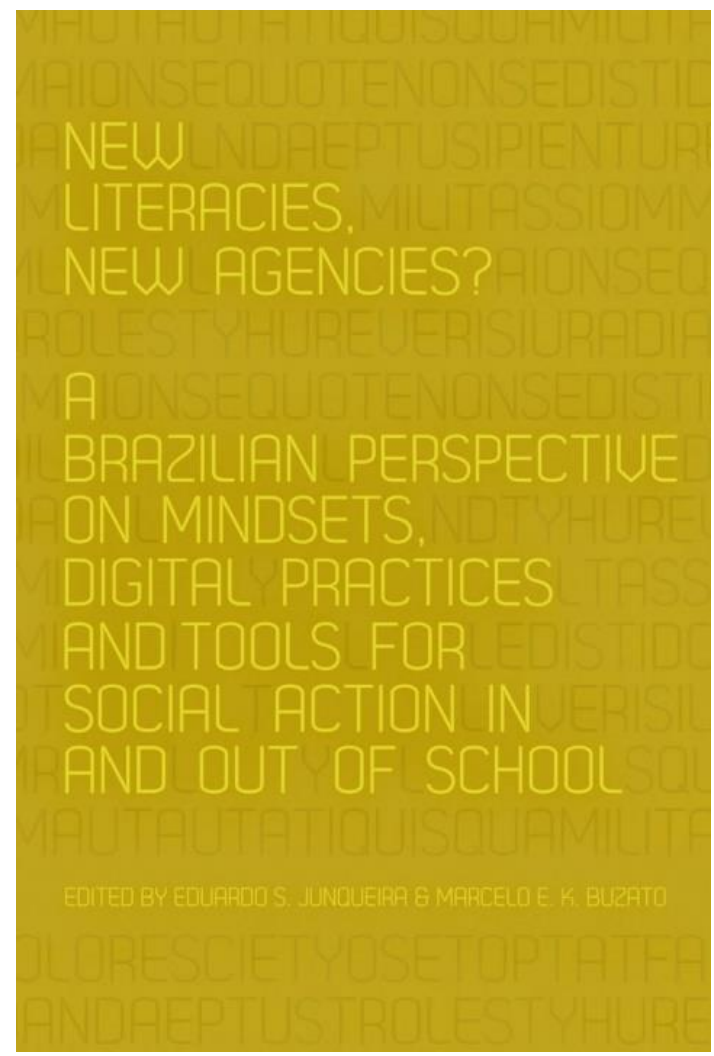

Foto de capa do livro New Literacies, new agencies?

New Literacies, new agencies? É um livro implicado em compreender como alunos, professores, estão agindo através dos novos letramentos digitais na educação brasileira. Em seus nove artigos, vemos autores que dobram e desdobram as noções, definições sobre agência e letramentos, para dialogar com suas pesquisas e análise de dados. A grande discussão é como podemos criar novas agências, novos letramentos a partir dos recursos que as tecnologias digitais nos oferecem, surgindo, assim, ambiência

para as pesquisas nos/dos/com os cotidianos, do modo dicotomizado criado pela ciência moderna para analisar a sociedade".” (SANTOS, R., 2015p. 13 apud ALVES, 2008, p.11)

\begin{tabular}{|l|l|l|l|l|l|l|}
\hline (C) Redoc & Rio de Janeiro & v.2 & n.2 & p. 198 & Maio/Agosto. 2018 & ISSN 2594-9004 \\
\hline
\end{tabular}




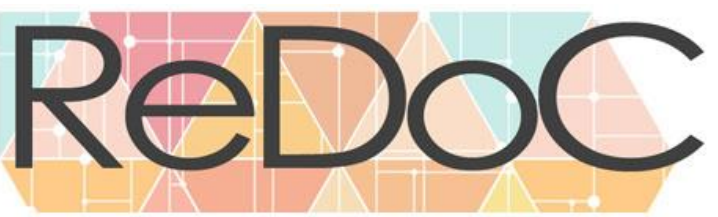

Revista Docência e Cibercultura

para que surjam novos atores que poderão fazer a mudança, lutar por suas causas sociais, para a construção de uma sociedade brasileira com menos desigualdade social.

Além disso, vemos diversos exemplos de como essas novas práticas educacionais, que vão de textos a sites colaborativos, representam um novo futuro para a educação brasileira, que atualmente encontra-se enfrentando diversas dificuldades, sejam elas de infraestrutura, falta de qualificação, ou má organização dos projetos por parte do governo. Um dos problemas que podemos ilustrar é o índice de reprovação nas escolas que não tem havido políticas públicas para resolver:

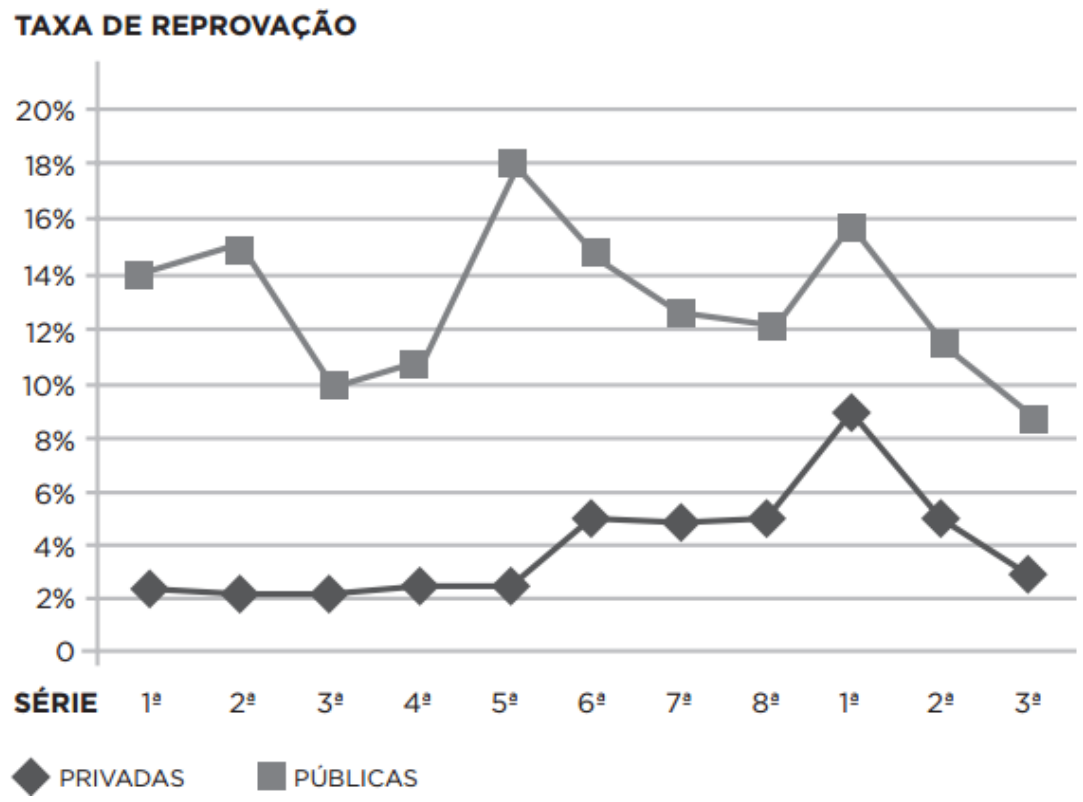

Gráfico ilustrativo a respeito das reprovações escolares ${ }^{5}$

Por isso, é mais do que importante que esse sistema passe por inovação, e que professores estejam qualificados e atualizados para essas mudanças. De acordo com o capítulo $7^{6}$ de Monte Mór, o Projeto Nacional na Educação dos Professores aponta que professores que ensinam línguas estrangeiras continuam a utilizar metodologias de ensino antigas, mantendo a centralidade no professor e não desenvolvendo a educação como uma forma de "empoderamento" e desenvolvimento de agência.

\footnotetext{
${ }^{5}$ Gráfico produzido por Diana Mandelert, especialista na área de repetência escolar.

${ }^{6}$ Chapter 7. The Development of Agency in a New Literacies Proposal for Teacher Education in Brazil
} 


\section{AGÊNCIA}

A partir da leitura de New Literacies, new agencies? Percebemos que existem diversas teorias que vários autores importantes produziram e discutiram, e podem convergir ou divergir a respeito do que pode ser Agência. Buzato no seu segundo capítulo ${ }^{7}$ (p.24) apresenta uma discussão elaborada a respeito das dicotomias e debates a respeito de agência. A primeira definição que ele nos apresenta é a Foucauldiana, em que agência significa lutar contra alguém ou alguma coisa para governar nossos atos. Mais tarde dialoga com Ahern (2001), dizendo que a agência é diferente de cultura para cultura, de época para época, de lugar para lugar.

Nesse contexto de debate sobre o que é e o que não é Agência, nos deparamos com uma grande quantidade de definições, porém, se não escolhermos uma entre tantas definições, não conseguiremos desenvolver argumentos e trabalhar com eles para compreender como essa teoria impacta em nossas vidas. Por isso, Buzato elege como melhores definições a de Giddens (1984), que é "a capacidade do indivíduo de fazer a diferença" em eventos e a de Ahearn (2001) com o conceito que é "a capacidade de agir mediada socioculturalmente".

A partir desses conceitos, Buzato abraça a definição de Ahearn, desenvolvendo que "essa capacidade é individual ou coletiva, material ou não-material, só humana e nãohumana" já nos adiantando que a agência internaliza dualismos, relacionada com poder e tecnologia.

Durante esse capítulo, o autor apresenta as linhas antitéticas de debate sobre a agência: condicional e normativo, individual ou coletivo, objetivismo e subjetivismo, tempo e espaço, e em cada um discute e dialoga com autores, porém aquele em que Buzato mais se apoia é Bruno Latour e a Teoria Ator-Rede, importante teoria para compreender as agências que emergem no contexto da Cibercultura.

${ }^{7}$ Chapter 2. Mapping Flows of Agency in New Literacies: Self and Social Structure in a Post-social World 


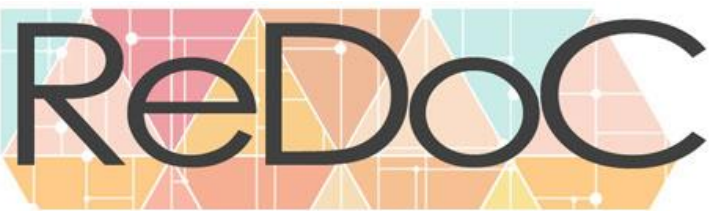

Revista Docência e Cibercultura

A Teoria Ator Rede é uma análise que "preconiza que as entidades são constituídas e adquirem seus atributos por meio de um conjunto de relações que estabelecem uma com as outras, existindo por meio dessas relações." (ALCADIPANI, TURETA, 2009) ${ }^{8}$, ou seja, essas entidades ${ }^{9}$ só estão em sua posição social, econômica, por meio dessa rede de relações. E de acordo com Latour (1996), objetos também fazem parte dessa rede, por conta de sua habilidade de transmitir, distorcer ações. $\mathrm{O}$ ator é aquele que age e sofre as ações na relação com o outro que pertence a mesma rede, sendo ele humano ou não humano.

Dessa forma, a TAR dialoga com a teoria de Agência, por nos lembrar de que tanto humanos quanto não humanos são atuantes, ou seja, ambos podem produzir realidades sociais, se trabalharem juntos.

Assim, devemos compreender que estamos em uma rede em que artefatos culturais também nos afetam, agem sobre nós. Por exemplo, ter uma boa conexão de rede de Internet em casa facilita a produção de trabalhos, a comunicação com outras pessoas, a pesquisa. Pessoas que não são letradas digitalmente, não estão vivendo os fenômenos ciberculturais e não são agentes digitais.

\section{MAPEAMENTO DOS CAPÍTULOS E ANÁLISE}

Cada capítulo pertence a diferentes autores, esses que participam de grupos de pesquisa que possuem seu modo de fazer pesquisa. O nosso Grupo de Pesquisa Docência e Cibercultura, adota uma metodologia da Pesquisa Formação, no qual o autor forma e se forma no contexto nos/dos/com os cotidianos. Cito Santos, E:

A ciberpesquisa-formação é uma metodologia de pesquisa qualitativa que legitima a educação online como campo de pesquisa-formação na cibercultura. Concebe o processo de ensinar e aprender a partir do compartilhamento de narrativas, sentidos e dilemas de docentes e pesquisadores pela mediação das interfaces digitais concebidas como dispositivos de pesquisa-formação (SANTOS, E, 2005, p.74).

\footnotetext{
${ }^{8}$ Disponível em: http://www.portalseer.ufba.br/index.php/revistaoes/article/view/11084/7997

${ }^{9}$ Termo que não reduz a possibilidade de que se refira a um ser humano ou não-humano.
} 


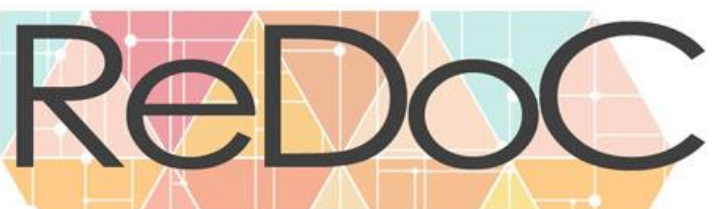

Revista Docência e Cibercultura

Logo, o Grupo de Pesquisa se preocupa em estudar, compreender os fenômenos ciberculturais e como eles se desdobram a favor da Educação. No nosso fazerpesquisa não coletamos dados, na verdade, coproduzimos com os praticantes culturais. E estes dados se dão em narrativas, em imagens, conversas. Deixo como imagem o infográfico produzido pelo GPDOC, a respeito da Pesquisa-Formação na Cibercultura:

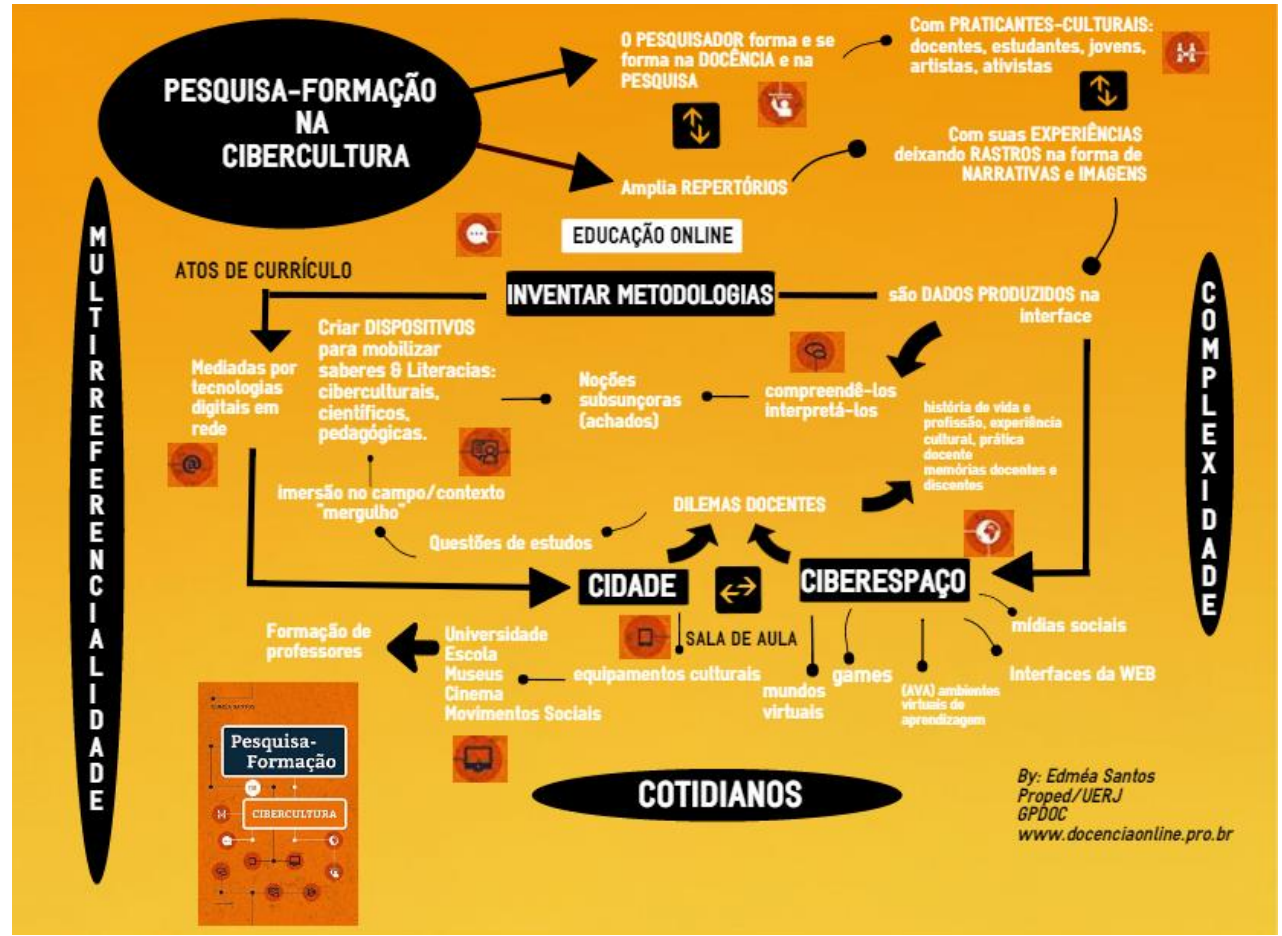

Infográfico produzido pelo Grupo de Pesquisa Docência e Cibercultura

No capítulo 8 Interactivity, Agency, and Mediation in $3 D$ Virtual Worlds, apresenta uma discussão sobre os pilares: Interatividade, Agência e Mediação, que são necessários para que haja ambiência formativa, de acordo com as autoras. Além disso, o texto mostra alunos construindo autoria e engajamento em novas práticas de letramento.

O conceito de Agência usado neste capítulo é o de Murray (1997), que "é a sensação experimentada pelo indivíduo quando suas ações é o resultado de sua escolha". Dessa forma, a agência vai emergir no momento em que alunos, em ambientes online, coproduzem práticas sociais. 


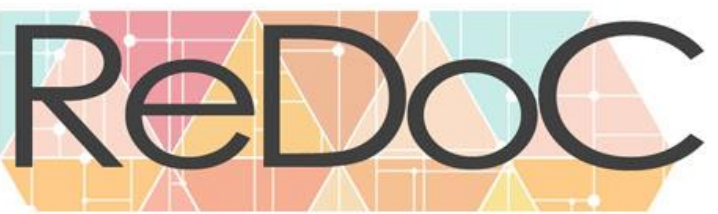

Revista Docência e Cibercultura

Os dispositivos de pesquisa utilizados são diários, conversas e diálogos que serão acionados com os alunos na disciplina "Educação Digital: Ensinando e Aprendendo no Mundo Digital", que tomará como ambiente virtual 3D o Second Life. A utilização desses dispositivos é fundamental e caro para o nosso fazerpesquisa, pois, os dados vão emergir a partir das narrativas dos praticantes culturais, que são o que utilizamos em nossas pesquisas.

Os resultados das aulas da disciplina no ambiente virtual 3D foram, primeiramente, a agência dos estudantes que emergiu a partir de sua participação, interação, autoria e produção de conhecimentos em grupo, incluindo o professor. Isso aconteceu "quando eles se apropriaram de conceitos teóricos e representaram no mundo virtual" (p.161), essa interação e participação foi alimentada pela mediação da professora. Em segundo lugar, o ambiente virtual proporcionou conforto aos praticantes culturais, sentimento de pertencimento, pois todos trabalharam unidos, e garantiu a interatividade, para que os estudantes pudessem construir conhecimentos em grupo, sem que fosse linear e mecânico.

Esse capítulo é um exemplo de uma Pesquisa-Formação, por ter como dados as narrativas dos praticantes culturais, e pelo pesquisador formar e se formar, junto com seus estudantes. A criação das noções sobre os conceitos debatidos foi coconstruída em uma mesma linearidade dos estudantes com o docente. Além disso, a mediação foi muito bem trabalhada, já que os praticantes culturais produziram bastante. Devemos destacar o conforto em que os alunos sentiram, por estarem usando avatares.

Vilson J. Leffa ${ }^{10}$, que possui Doutorado em Linguística Aplicada pela Universidade do Texas e mais recentemente concentrou-se no estudo das novas tecnologias no ensino de línguas, incluindo a produção de objetos digitais de aprendizagem e o ensino a distância, vai trabalhar melhor essa questão do Avatar no capítulo 4. Este é divido em três questões a serem respondidas: a primeira é se humanos podem atingir seus objetivos se ferramentas não estão lá para ajudá-lo, a segunda é se agentes e mediadores podem trocar de lugar e assumir o papel um do outro e a diferença

${ }^{10}$ http://lattes.cnpq.br/7239316228662609 


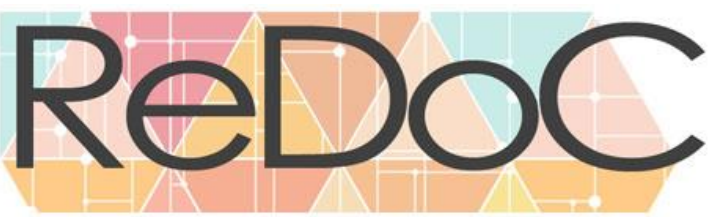

Revista Docência e Cibercultura

entre eles e a última é sobre os avatares, que às vezes transformam humanos em agentes, e às vezes ações em ferramentas.

Para responder a primeira questão, Leffa diz que ferramentas e objetivos estão relacionados, dependendo um do outro para a sua existência. Pois existe intencionalidade quando adquirimos uma ferramenta, que é para atingir algum objetivo. E, Leffa afirma que "objetivos, por outro lado, são inalcançáveis se as ferramentas não estão lá para ajudar.” (p.74). Dessa forma, os professores deveriam garantir essas ferramentas para os alunos atingirem seus objetivos.

Na segunda questão, é argumentado que agentes podem fazer algo não só para eles, mas para o interesse de outras pessoas, funcionando como ferramentas, ou seja, ajudando outras pessoas a alcançar os seus objetivos. Esse fato não diminui esses agentes, na verdade demonstra que eles podem passar de agentes, quem faz coisas para si, à mediadores, que é quem trabalha para outras pessoas.

Na terceira questão, o autor começa dizendo que um avatar "é a representação gráfica de uma personalidade digital", que pode ser parecido ou não com a pessoa que representa. O avatar faz referência a antigos artefatos culturais, como as máscaras. Essas que vestimos para nos manter profissionais e escondendo seus sentimentos ruins. Outra referência é aos fantoches, em que não se esconde quem é, mas transfere conforto e mais dialogia. A máscara serviria como agente e o fantoche seria o mediador. Porém, os dois artefatos culturais teriam a mesma potencialidade que é de empoderar as pessoas e garantem o conforto para o praticante cultural, assim como vimos no capítulo analisado anteriormente.

A conclusão é de que o avatar tem potencialidades para o ensino e a aprendizagem, seja usado como máscara, seja usado como fantoche. Ele garante que praticantes possam ser o que quiserem, o limite é a sua imaginação.

O autor tem sucesso em seus exemplos dados, e traz questões teóricas interessantes para o livro, porém a escolha pela palavra "ferramenta" é complicada, pois cotidianistas entendem "ferramenta" apenas como uma extensão do músculo, nada mais. 


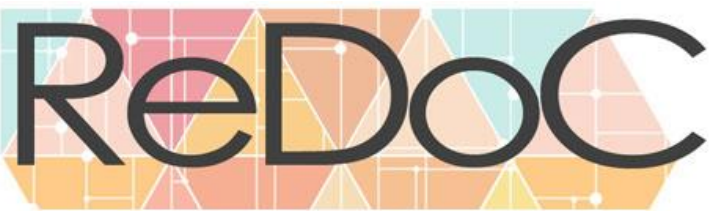

Revista Docência e Cibercultura

Já no capítulo 5 If You Can't Play, Don't Come Down to the Playground!, escrito por Luiz Fernando Gomes, que faz parte do GT Linguagem e Tecnologia da ANPOLL e estuda Linguística Aplicada em Linguagem e Tecnologia ${ }^{11}$, nos apresenta uma diferente análise de duas postagens do site Zuei Muito, que utilizam a paródia e a remixagem para construir suas imagens e produzir sentido. O objetivo específico é compreender a autoria do discurso humorístico dos dois textos.

Em seu texto, Gomes entende Agência como "uma das características salientes dos novos letramentos, e está ligada à necessidade de entender códigos, convenções e valores, de lidar com os limites, de subverter, criticar e reagir ao mundo envolta de nós." (p. 89). Além disso, argumenta citando Gee, Hull e Lankshear que para se tornar um letrado é preciso começar lendo, e mais tarde ter práticas sociais de discurso, interação que vão afetar a sua maneira de estar no mundo, e, consequentemente, pensar nele de novas formas.

O autor vai escolher a argumentação de Aherns (2001), a respeito do conceito de Agência, a qual é preciso intencionalidade, responsabilidade, expectativa de se conseguir reconhecimento. Essas características vão aparecer no humor, que é um conceito explorado no capítulo, Gomes diz que o humor será uma agência quando criticar alguns costumes, a sociedade em si e a política. E essa crítica se dará através da paródia e da remixagem. A primeira é uma forma de satirizar as ideias originais do autor original, criando uma nova versão, a segunda é a combinação de dois artefatos culturais, resultando em uma mistura criativa. É importante destacar a afirmação do autor que toda leitura é uma forma de remixagem, trazendo assim as opiniões do autor original e de quem lê, o que podemos ver isso em citações, resenhas, entre outros.

O site Zuei Muito foi escolhido por razões pessoais e pelo slogan ${ }^{12}$ "se você não sabe brincar, não desça pro play”, que chamou a atenção de Gomes, dizendo que a

\footnotetext{
${ }^{11}$ Informações tiradas do site: http://www.bv.fapesp.br/pt/pesquisador/103859/luiz-fernando-gomes/

12 Trago em português para que tenha coerência com a língua utilizada neste texto, já que a expressão originalmente é em Língua Portuguesa e foi traduzida para o Inglês.
} 


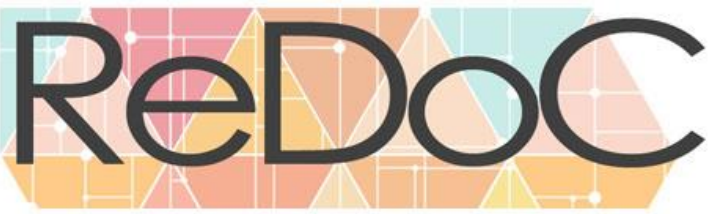

Revista Docência e Cibercultura

afirmação expressa a sátira desenvolvida pelos autores das postagens. Estes que não são explícitos e/ou mencionados no blog.

A primeira imagem analisada é uma crítica em forma de paródia à respeito dos fast foods, comidas que fazem mal à saúde e obesidade, utilizando um slogan de um restaurante famoso em formas grandes para trazer a ideia da silhueta de duas pessoas obesas. Já a segunda é um remix do mesmo slogan, porém, colocado como epitáfio. As duas imagens trazem diferentes leituras e significados, mostrando a criatividade de quem às produziu e que efeitos surgem na leitura delas.

Considero subjetiva a escolha do site e pouco discorrido a respeito das razões pessoais do autor a respeito disso. Creio que seria mais autoral se soubéssemos quem são os autores das imagens, para compreender o contexto dos praticantes culturais e as razões de se fazer a crítica a respeito da obesidade e fast foods.

A autoria será mais saliente no capítulo 6 de Ana Elisa Ribeiro, doutora em Linguística Aplicada (Linguagem e tecnologia) e mestre em Estudos Linguísticos, e Carla Viana Coscarelli, participa do Núcleo de Pesquisa Lingtec e tem doutorado em Estudos Linguísticos $^{13}$, em que as autoras vão analisar o que três grupos, de diferentes perfis, vão produzir em três textos. Esses grupos utilizaram um software de nuvem, para editar seus textos.

O conceito sobre Agência apresentado aqui é o de Bazerman (2006), que será inserida no contexto da escrita, que "está imbuída de agência". Escrever, discutir, reescrever, editar, são ações que acionam a agência de dos atores, que são os grupos.

O primeiro grupo não tinha experiência com a escrita colaborativa e não possuíam letramento digital. É composto por alunos recém-chegados na Faculdade, a tarefa deles era escrever versões iniciais de Projetos de Pesquisa, em que fossem apresentados questões da pesquisa, objetivos e metodologia.

O segundo já possuía um nível mais alto de experiência, esse grupo se compõe por estudantes do Mestrado. O objetivo destes estudantes era de produzir uma resenha de algum livro, e ela seria publicada para revista científica.

\footnotetext{
${ }^{13}$ http://lattes.cnpq.br/8886697697917438
} 


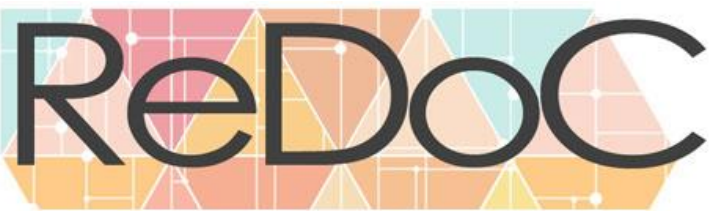

Revista Docência e Cibercultura

O último, formado por professores, alguns com mestrado, outros com doutorado, já era mais letrado, com muita experiência de escrita colaborativa e tinham facilidade com os ambientes virtuais. Eles foram convidados a desenvolver um artigo, para leitores que seriam professores das escolas fundamental e médio.

Os resultados foram que o primeiro grupo dos estudantes recém-chegados não atingiu o que era esperado, o pouco letramento digital não levou a um nível de agência que chegasse ao que foi proposto. No caso do segundo grupo, a produção da resenha não foi satisfatória, pela falta de familiaridade com o software e por falta de agência e colaboração. Já os professores conseguiram cumprir a tarefa, produzindo um texto de qualidade, com colaboração e autoria, mostrando agência e letramento digital, por apresentarem poucas dificuldades.

A autoria, a colaboração a familiaridade com o Google Docs - entidade não humana que age na rede de colaboração - são elementos importantes que os praticantes dessa pesquisa precisariam ter para que sua agência emergisse e atingisse o nível esperado pelas pesquisadoras.

Podemos perceber que a Teoria Ator-Rede aparece quando o Google Docs é fundamental para garantir que se produza de forma colaborativa, porém só se obtiverá sucesso com esse software se o praticante cultural for letrado digitalmente, se tiver colaboração.

A respeito da seleção de grupos, considero que seria melhor trabalhar com praticantes que estão já cursando a graduação e preparando-se para se autorizar em seu trabalho final, a Monografia. Esse momento é desafiador para a maioria deles, pois é um grande obstáculo quando não se está acostumado a escrever, reescrever, editar um trabalho científico.

Um trabalho de colaboração, coletividade será apresentado no capítulo 3 de Junqueira, em que estudantes vão se engajar com novos letramentos digitais em seu laboratório de informática.

O conceito explorado de Agência é o de Sewell (1992), em que agência é coletiva e individual no sentido "que implica a capacidade de coordenar suas ações com os outros, 


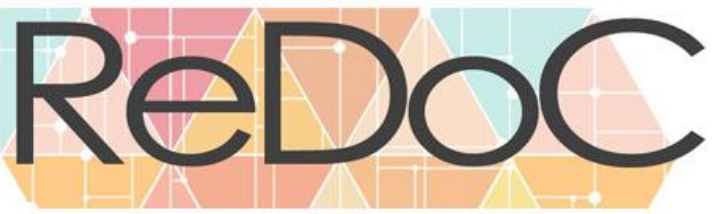

Revista Docência e Cibercultura

para formar projetos coletivos, persuadir (...)", ou seja, é possível que os alunos adquirissem agência trabalhando em coletivo.

Além disso, Sewell ainda diz que recursos não humanos são objetos que podem ser usados para conquistar ou manter poder. Para Junqueira, isso significa que "situações com poucos recursos podem ser transformadas por atores" para que consigam chegar aos seus objetivos. Essa transformação é a agência.

Apesar de cada praticante ter direito ao seu computador, por conta do programa Um Computador por Aluno, no laboratório de informática, Junqueira diz que a agência deles emergirá a partir de relações sociais em grupo e de seus novos letramentos digitais. Dessa forma, os estudantes aprendem a desenvolver narrativas e páginas web para concluir um projeto da escola. Essa aprendizagem se dá com uma tutora, e às vezes por falta de mediação dela, outros estudantes assumem o papel de tutor, ensinando os outros a trabalhar nos ambientes virtuais. O que demonstra que esse era um grupo muito independente e unido.

Importante destacar que Junqueira diz que essa experiência foi importante para que os estudantes pudessem desenvolver letramentos digitais, já que poucos, devido à pobreza, têm computadores em casa. Porém os recursos ainda eram muito escassos na escola. E, a partir dessas dificuldades, os praticantes culturais criaram uma Estratégia (CERTEAU, 1984) para que eles pudessem trabalhar em grupo, e menos em individual, ajudando nas deficiências que o outro tinha, seja de escrever, de operar softwares, etc.

O capítulo é muito bem escrito e traz uma reflexão diferente em que pensa mais em coletividade, e como a agência e o letramento científico se dariam em situações de extrema pobreza. Porém, acredito que o pesquisador poderia ter sido o tutor desses praticantes culturais, e poderia ter atuado para contribuir com os letramentos científicos deles. A observação do pesquisador leva à crítica da tutora, que não deu a atenção necessária para os alunos, e seria interessante ter alguma narrativa dela, ou até do próprio pesquisador que pudesse explicar a ausência.

Os capítulos analisados aqui possuem quadros teóricos diferentes e trabalham com seus dados de acordo com seu fazerpesquisa. Porém, eles se unem no momento que se 


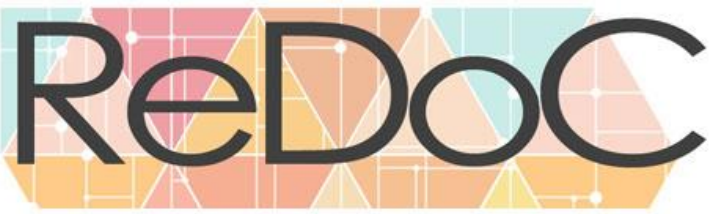

Revista Docência e Cibercultura

torna claro a importância do desenvolvimento da agência através dos letramentos científicos digitais em rede para a educação brasileira.

Escolhi trabalhar na análise com aqueles que possuíam análise de dados e que dialogavam entre si. Essa escolha se baseia em manter o texto mais coeso. Outros capítulos aparecerão na Conclusão, como o capítulo 7 e os primeiros capítulos que estão na Introdução.

\section{CONCLUSÃO}

Com a análise e o mapeamento dos capítulos do livro, podemos inferir que a produção de novas práticas, novos letramentos, a mediação dos professores garante que praticantes culturais possam agir, escrever, reescrever, coconstruir pensamentos, e dar significados a elementos que estão do outro lado da tela, que estão imersos no Ciberespaço em rede. A partir disso, eles podem se tornar atores, que são aqueles que querem mudar a realidade em que estão, de acordo com Foucalt. E vimos que isso pode ser de forma individual ou coletiva.

No capítulo 7 The Development of Agency in a New Literacies Proposal for Teacher Education in Brazil temos uma investigação a respeito dos problemas de ensino e aprendizagem de professores de língua estrangeira. Estes que, por uma passagem pela graduação sem a discussão de agência, fazem de suas aulas estudos a respeito de vocabulários e elementos gramaticais, ao invés de propor um entendimento do texto em si. A autora, Walkyria Monte Mór, trabalha com as ideias de Freire que é preciso compreender historicamente o porquê de a Educação Brasileira ter tantas deficiências. E ela trabalha com diferentes momentos históricos do Brasil: o ensino e aprendizagem dos Jesuítas, o relacionamento colonial com Portugal e o período de Ditadura, de forma que os três representam opressões para a Educação. Por isso, precisamos atingir a agência e vencer essa opressão (FREIRE, 1987), através de novos estudos sobre letramento científico. 


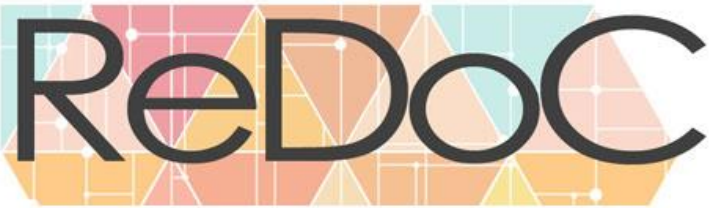

Revista Docência e Cibercultura

Acreditamos que através dos diversos exemplos que foram apresentados no livro, está claro como os novos letramentos científicos podem servir para melhorar a situação da Educação Brasileira. Um dos que mais chama atenção pra isso é a do capítulo 3, em que estudantes que são socialmente estratificados, que enfrentam inúmeras dificuldades, podem também trabalhar, atingir agência.

\section{REFERÊNCIAS}

AHEARN, L. M. (2001). Language and agency. Annual Review of Antropology. 30(1), 109-137.

ALCADIPANI,

TURETA, disponível em: http://www.fcc.org.br/pesquisa/publicacoes/eae/arquivos/1765/1765.pdf

ALVES, Nilda. Sobre o movimento das pesquisas nos/dos/com os cotidianos. In: OLIVEIRA, Inês Barbosa; ALVES, Nilda (Orgs.). Pesquisa no/do cotidiano das escolas: sobre redes de saberes. Petrópolis: DP\&A, 2008.

BAZERMAN, C. (2006a). Gênero, agência e escrita. São Paulo, Brasil: Cortez.

BAZERMAN, C. (2006b). Gêneros textuais, tipificação e interação. São Paulo, Brasil: Cortez.

DE CERTEAU, M. (1984). The practice of everyday life. Berkeley, CA: University of California Press.

FOUCALT, M. (1978). The history of sexuality. New York, NY: Patheon.

FREIRE, P. (1987). Pedagogia do oprimido. (28nd ed.). Rio de Janeiro, Brasil: Paz e Terra.

GOMES, Luiz Fernando. If You Can't Play, Don't Come Down to the Playground!. 2013.

JUNQUEIRA, Eduardo S. Peer-based Work and Agency in the School Computer Lab: Learning New Literacies as a Collective Practice.

LANKSHEAR, C., \& Knobel, M. (2003). New literacies: Changing knowledge and clasromm practice. Buckingham, England: Open University Press. 


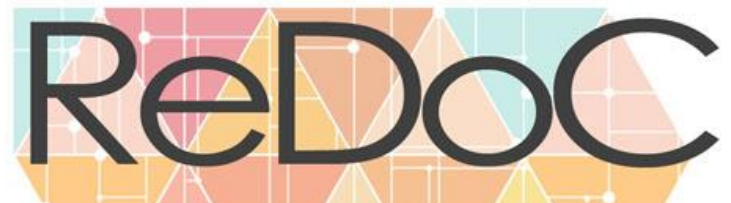

Revista Docência e Cibercultura

LATOUR, B. (1996). On interobjectivity. Mind, Culture, and Activity, 3 (4), 228-245.

LEFFA, Vilson J. Distributed Agency in Avatar-based Learning. 2013.

MANDELERT, Diana. Reprovação em Escolas de Prestígio, disponível em: http://www.fcc.org.br/pesquisa/publicacoes/eae/arquivos/1765/1765.pdf. 2010.

MONTE MÓR, Walkyria. The Development of Agency in a New Literacies. 2003.

RIBEIRO, Ana Elisa., COSCARELLI, Carla Viana. Agency, Collaborative Writting, and ICTs: A Brief Analysis of Three Cases of Textual Production Using Google Docs.

RIBEIRO, Mayra. A sala de aula no contexto da Cibercultura: Formação docente e discente em Atos de Currículo. 2015

SANTOS, E.; ROSSINI, Tatiana. Interactivity, Agency and Mediation in 3D Virtual Worlds. 2013.

SANTOS, Rosemary. Formação de Formadores e Educação Superior na Cibercultura: Itinerâncias de Grupos de Pesquisa no Facebook. 2015.

SEWELL, W. H. (1992). A theory os structure: Duality, agency and transformation. American Journal of Sociology, 98(1), 1-29. 